\title{
Belatacept for prevention of acute rejection in adult patients who have had a kidney transplant: an update
}

This article was published in the following Dove Press journal:

Biologics:Targets and Therapy

I November 2012

Number of times this article has been viewed

\section{David Wojciechowski \\ Flavio Vincenti \\ Kidney Transplant Service, University of California, San Francisco, CA, USA}

Correspondence: Flavio Vincenti University of California, San Francisco, Kidney Transplant Service, 505 Parnassus Avenue, Room 884M, San Francisco, CA $94143-0780$, USA

Tel + I 4I5 353 I322

Fax + I 4I53538974

Email flavio.vincenti@ucsfmedctr.org
Abstract: In June 2011, the US Food and Drug Administration approved belatacept for the prophylaxis of organ rejection in adult kidney transplant recipients. This review discusses the use of belatacept for the prevention of acute rejection as part of a maintenance immunosuppression regimen. Belatacept is a selective costimulation blocker designed to provide effective immunosuppression while avoiding the toxicities associated with calcineurin inhibitors. Phase III trial data have demonstrated that belatacept is noninferior to cyclosporine in 1-year patient and allograft survival. Three-year data demonstrate an ongoing improvement in mean measured glomerular filtration rate in belatacept-treated versus cyclosporine-treated patients. However, the rate of acute rejection was higher in belatacept-treated patients compared with cyclosporine. Specifically, there was a higher incidence of Banff type II rejections in patients treated with belatacept. Despite the higher Banff grade, rejections on belatacept were not associated with other factors associated with poor outcomes, such as the development of donor-specific antibodies or reduced estimated glomerular filtration rate. One safety issue that must be considered when using belatacept is the potential for increased risk of post-transplant lymphoproliferative disease. There were more cases of post-transplant lymphoproliferative disease in belatacept-treated patients, especially in recipients seronegative for Epstein-Barr virus or patients treated with lymphocyte-depleting agents. Therefore, belatacept can be recommended for use in EpsteinBarr virus antibody-positive recipients.

Keywords: belatacept, kidney transplant, acute rejection

\section{Introduction}

The introduction of calcineurin inhibitors (CNI) followed by mycophenolate mofetil resulted in an era of improved efficacy of maintenance immunosuppression. Short-term acute rejection rates declined and 1-year outcomes improved. Despite short-term success, the long-term renal allograft survival has not shown a similar rate of improvement. ${ }^{1}$ The 1-year renal allograft survival rate is $95 \%$ and $89 \%$ for recipients of living and deceased donor kidneys, respectively. ${ }^{2}$ At 5 years post-transplantation, renal allograft survival falls to a disappointing $80 \%$ and $67 \%$ for living and deceased donor kidney recipients, respectively. ${ }^{2}$

Cardiovascular disease remains the leading cause of death post-transplantation, ${ }^{2}$ while chronic allograft nephropathy (a nonspecific term) remains the most common cause of late allograft loss. ${ }^{3}$ With the introduction of immunosuppression protocols which include a CNI, the data have suggested that CNIs are a significant contributor to the progression of chronic allograft nephropathy and hasten long-term allograft loss. ${ }^{4}$ Given the concern about long-term CNI exposure on renal function, strategies 
have evolved to eliminate or reduce CNI exposure as the acute rejection risk declines over time. ${ }^{5-9}$ However, newer data suggest that perhaps it is not a direct CNI effect but rather a subacute, chronic alloimmune response (such as that occurring with the development of donor-specific antibodies) that is playing a dominant role in late allograft loss. ${ }^{10-15}$ Strategies to minimize CNI exposure post-transplantation may contribute to this effect.

Belatacept (Nulojix ${ }^{\circledR}$; Bristol-Myers Squibb, Princeton, NJ), a fusion protein and selective costimulation blocker, was approved in June 2011 by the US Food and Drug Administration for the prophylaxis of organ rejection in adult patients receiving a kidney transplant. It is given as a 30-minute infusion, which can be done either in an infusion center or in the home. Belatacept was developed to provide effective immunosuppression as an alternative to CNIs and thus avoid the toxicities associated with CNIs. This review summarizes the outcome data, with an emphasis on acute rejection, from the clinical trials of belatacept in renal transplant recipients as part of a CNI-free regimen.

\section{Costimulation blockade with belatacept}

The CD28/B7 (CD80 and 86) costimulation pathway (Figure 1) is an essential signal for T-cell activation. It is one of several T-cell costimulatory pathways that are required to regulate the different T-cell responses in transplant models. ${ }^{16}$ After 25 years of research, the fusion receptor protein, CTLA4-Ig (abatacept), a competitive antagonist for CD28 blocking CD80/CD86 binding, was approved for human use in the treatment of rheumatoid arthritis. ${ }^{17}$ Early experiments with costimulation blockade in transplantation were mixed. Prolongation of graft survival or induction of tolerance using costimulation blockade in rodent transplantation experiments could not be reproduced in nonhuman primates. ${ }^{18,19}$ CTLA4-Ig did not achieve as good affinity with CD86 as with CD80 and was the likely cause of failure in a more stringent animal model. ${ }^{18}$
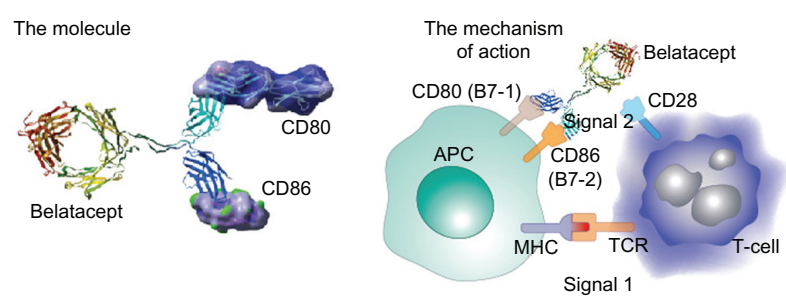

Figure I Signal I is antigenic, whereas signal 2 is costimulatory from the antigenpresenting cell.

Note: Following costimulation, cytokines such as interleukin-2 drive T-cell division, causing clonal expansion.

Abbreviations: MHC, major histocompatibility complex; TCR, T-cell receptor.
Belatacept, a reengineered CTLA4-Ig with two amino acid substitutions in the CTLA4 binding domains, binds CD80 two-fold better and CD86 four-fold better than CTLA4-Ig and provides 10-fold more potent inhibition of T-cell activation in vitro versus CTLA4-Ig. ${ }^{20}$ The in vitro superiority of belatacept in blocking T-cell responses was confirmed by better survival of renal allografts in a nonhuman primate model. ${ }^{18}$ In these experiments, a CNI-free regimen with belatacept and a combination of an anti-interleukin-2 receptor antibody and maintenance therapy with mycophenolate mofetil and steroids resulted in marked prolongation of survival of renal allografts. ${ }^{18}$

Given these encouraging data, clinical trials were undertaken, and the initial Phase II data was published in $2005 .{ }^{21}$ In this multicenter trial, which compared the safety and efficacy of two dosing regimens of belatacept versus cyclosporine, belatacept was found to be noninferior (with a noninferior margin set at $20 \%$ ) to cyclosporine as a means of preventing acute rejection after renal transplantation, with five (7\%) and four $(6 \%)$ patients treated with a more intensive (MI) and less intensive (LI) belatacept regimen, respectively, experiencing acute rejection at 6 months compared with six (8\%) cyclosporine-treated patients.

In regard to safety, it was also noted that three patients receiving the $\mathrm{MI}$ regimen developed post-transplant lymphoproliferative disorder (PTLD) compared with one patient receiving cyclosporine. Two of these patients developed PTLD after belatacept had been replaced with conventional immunosuppression (tacrolimus, mycophenolate mofetil, and corticosteroids). Two of the three patients had primary Epstein-Barr virus (EBV) infections, while the third received lymphocyte-depleting therapy with muronomab-CD3 for acute rejection. In the 5-year long-term extension trial, one patient treated with cyclosporine developed PTLD in year 4 after transplantation, compared with no patients treated with belatacept. $^{22}$

\section{Phase III trials: BENEFIT and BENEFIT-EXT}

Given the promising Phase II trial results, two Phase III trials were undertaken. Both trials have provided important data on the role of belatacept for the prevention of acute rejection as part of a CNI-free regimen.

\section{BENEFIT}

The first study, Belatacept Evaluation of Nephroprotection and Efficacy as First-line Immunosuppression Trial (BENEFIT), ${ }^{23}$ was a multicenter, randomized, 
active-controlled, parallel-group Phase III trial. Adult patients receiving a living donor or standard criteria deceased donor kidney were eligible. First-time patients with a panel reactive antibody $\geq 50 \%$, retransplants with a panel-reactive antibody $\geq 30 \%$, recipients of prior or concurrent nonrenal solid organ transplants, and recipients of extended criteria donor kidneys were excluded. Patients were randomized to one of three regimens for maintenance immunosuppression, ie, a MI regimen of belatacept, a LI regimen of belatacept, or cyclosporine (Figure 2). Patients in all treatment arms received basiliximab induction and were maintained on mycophenolate mofetil and corticosteroids. Lymphocytedepleting therapy was permitted in the cyclosporine group for delayed or anticipated delayed graft function. Patients with acute rejection $\geq$ Grade IIB could be treated with T-celldepleting therapy at the investigator's discretion.

The trial was designed with three coprimary outcomes, ie, composite patient and graft survival, a composite renal impairment endpoint, and incidence of acute rejection. The noninferiority margin for patient and graft survival and for acute rejection was set at $10 \%$ and $20 \%$, respectively. Protocol biopsies were performed at implantation and at week 52 . A total of 527 patients were randomized to three treatment groups, transplanted, and completed the initial 12-month treatment phase. Recipient demographics and baseline characteristics as well as donor characteristics were similar between the three groups.
Both belatacept regimens were noninferior to cyclosporine for the primary endpoint of patient and graft survival. At 1 year, patients enrolled in the MI, LI, and cyclosporine treatment groups had 95\%, 97\%, and 93\% patient and graft survival, respectively. The mean measured glomerular filtration rate (GFR) was $65 \mathrm{~mL} / \mathrm{min} / 1.73 \mathrm{~m}^{2}, 63.4 \mathrm{~mL} / \mathrm{min} / 1.73 \mathrm{~m}^{2}$, and $50.4 \mathrm{~mL} / \mathrm{min} / 1.73 \mathrm{~m}^{2}$ in the MI-treated, LI-treated, and cyclosporine-treated patients, respectively $(P<0.0001$ for both MI and LI versus cyclosporine). The prevalence of chronic allograft nephropathy on protocol biopsies was lower in belatacept-treated patients compared with cyclosporine-treated patients (18\% MI, 24\% LI, 32\% cyclosporine).

There was a higher incidence of acute rejection at 12 months in the belatacept-treated groups compared with the cyclosporine-treated group (22\% MI, 17\% LI, $7 \%$ cyclosporine). The incidence of acute rejection met the noninferiority cutoff for the LI group versus the cyclosporine group, but not for the MI group versus the cyclosporine group. Almost $100 \%$ of these rejections occurred within the first 6 months post-transplantation. Belatacept-treated patients had more type IIa and IIb rejections compared with cyclosporine-treated patients but were not associated with an increase in donor-specific antibody. The mean measured GFR at month 12 was higher in belatacept-treated patients with acute rejection compared with cyclosporine-treated patients without acute rejection (Figure 3).

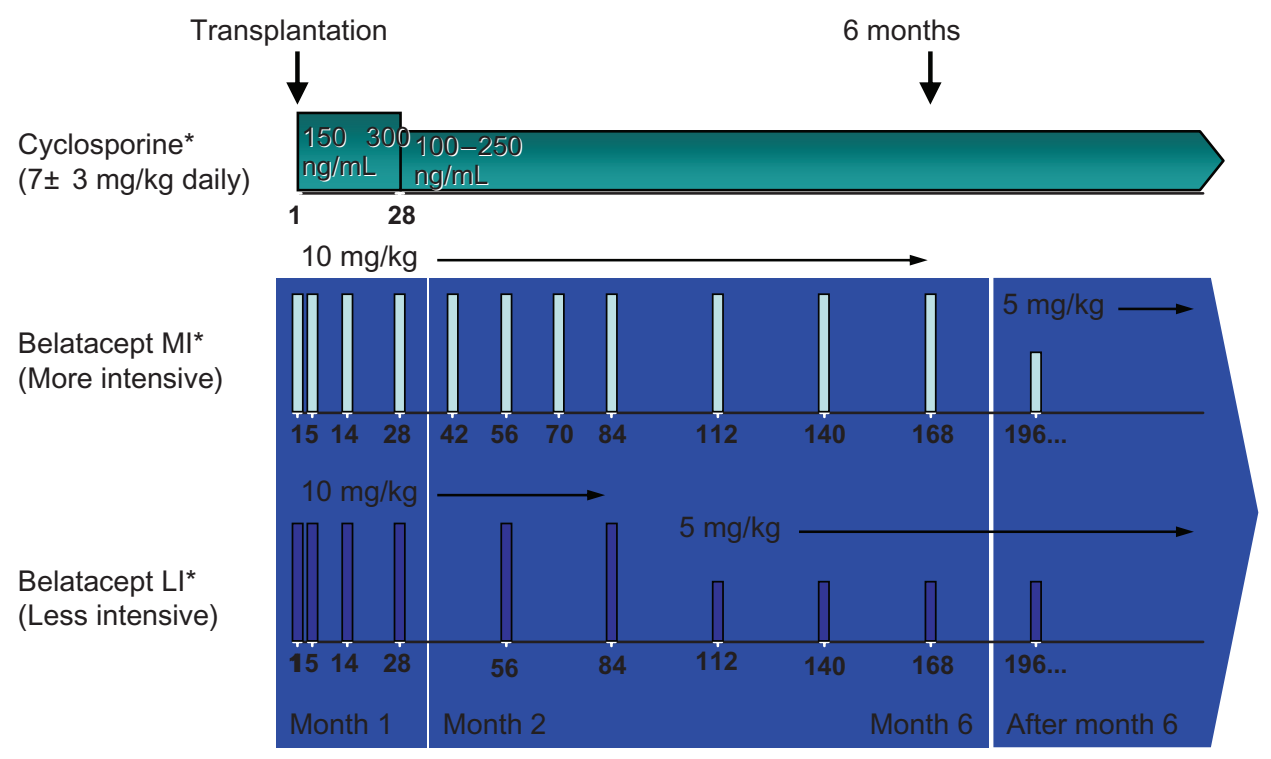

Figure 2 All patients received induction with basiliximab and maintenance therapy with mycophenolate mofetil and corticosteroids.

Notes: Patients randomized to receive cyclosporine were started at $7 \pm 3 \mathrm{mg} / \mathrm{kg}$ daily in divided doses with a goal trough of I50-300 ng/mL for the first month followed by $100-250 \mathrm{ng} / \mathrm{mL}$ thereafter. Ml-treated patients received belatacept at $10 \mathrm{mg} / \mathrm{kg}$ for the first 168 days and $5 \mathrm{mg} / \mathrm{kg}$ from day 196 onwards. LI-treated patients received belatacept at $10 \mathrm{mg} / \mathrm{kg}$ for the first 84 days and $5 \mathrm{mg} / \mathrm{kg}$ from day $1 \mathrm{I} 2$ onward. *All patients received basilixmab induction, mycophenolate mofetil, and corticosteroid-taper. 


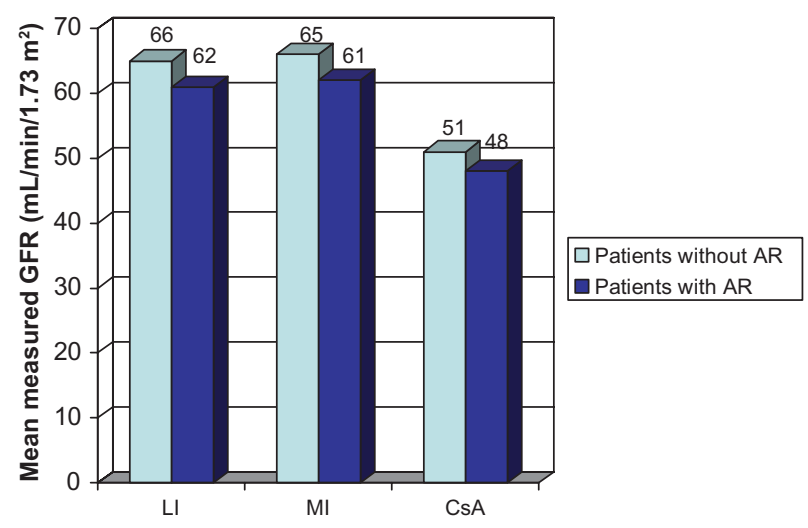

Figure 3 Measured glomerular filtration rate (GFR) by month 12 in patients with and without rejection in BENEFIT.

Abbreviations: AR, acute rejection; BENEFIT, Belatacept Evaluation of Nephroprotection and Efficacy as First-line Immunosuppression Trial; CsA, cyclosporine; $\mathrm{LI}$, less intensive; $\mathrm{MI}$, more intensive.

Belatacept-treated patients had a significantly lower mean blood pressure (MI 133/79 $\mathrm{mmHg}$, LI 131/79 mmHg) compared with cyclosporine-treated patients $(139 / 82 \mathrm{mmHg}$, $P \leq 0.0273$ for MI or LI versus cyclosporine in all comparisons). The mean change in non-high-density lipoprotein cholesterol from baseline was significantly different in belatacept-treated patients (MI $0.21 \mathrm{mmol} / \mathrm{L}, \mathrm{LI} 0.21 \mathrm{mmol} / \mathrm{L}$ ) compared with cyclosporine-treated patients $(0.47 \mathrm{mmol} / \mathrm{L}$, $P=0.0115$ for MI and $P=0.0104$ for LI versus cyclosporine). The incidence of new-onset diabetes mellitus after transplant (NODAT) was not significantly different between the three groups, ie, MI 7\%, LI 4\%, and cyclosporine 10\% ( $P=\mathrm{NS}$ for MI or LI versus cyclosporine).

Two-year and 3-year data are available for BENEFIT. ${ }^{24,25}$ Between months 12 and 24, a total of eight patients had an acute rejection episode (MI, $n=4$; cyclosporine, $n=4$ ) for a total of $24 \%$ (MI) and 9\% (cyclosporine) from baseline to month $24 .{ }^{24}$ The 3-year data demonstrate that there were no new cases of acute rejection in the belatacept groups from year 2 to year $3 .{ }^{25}$ However, one patient in the cyclosporine group experienced acute rejection after year 2. By year 3, donorspecific antibodies occurred more commonly in cyclosporinetreated patients (MI 6\%, LI 5\%, cyclosporine 11\%). In patients who had an acute rejection episode by year 3 , the proportion of patients with donor-specific antibodies was 12\% (MI), $8 \%(\mathrm{LI})$, and 19\% (cyclosporine). In regard to renal function at year 3, the mean calculated GFR was $65.2 \pm 26.3 \mathrm{~mL} / \mathrm{min} / 1.73 \mathrm{~m}^{2}$ (MI), $65.8 \pm 27.0 \mathrm{~mL} / \mathrm{min} / 1.73 \mathrm{~m}^{2}$ (LI), and $44.4 \pm$ $23.6 \mathrm{~mL} / \mathrm{min} / 1.73 \mathrm{~m}^{2}$ (cyclosporine, $P<0.0001 \mathrm{MI}$ or LI versus cyclosporine). The mean calculated GFR in belatacept-treated patients was consistently higher compared with cyclosporinetreated patients throughout the study period.
The issue of PTLD, which was raised in the Phase II trial, also merits a discussion from the Phase III data. By 12 months, one patient, two patients, and one patient in the MI, LI, and cyclosporine groups developed PTLD, respectively. Additionally, between years 1 and 2, two additional patients in the MI group developed PTLD affecting the central nervous system. Four of the six patients who developed PTLD had known risk factors. One patient had EBV-negative serology pretransplant, one patient received lymphocyte-depleting therapy as treatment for an acute rejection, and two patients had EBV-negative serology and received lymphocyte-depleting therapy. Lastly, two patients with EBV-negative serology received transplants from EBVseropositive donors. No new cases of PTLD were reported in any group between years 2 and $3 .{ }^{25}$

\section{BENEFIT-EXT}

The second study was the Belatacept Evaluation of Nephroprotection and Efficacy as First-line Immunosuppression Trial-EXTended criteria donors (BENEFIT-EXT), ${ }^{26}$ a randomized, multicenter Phase III trial conducted in patients who received a kidney transplant from an extended criteria donor defined as: aged $\geq 60$ years; aged $\geq 50$ years with at least two other risk factors (cerebrovascular accident, hypertension, serum creatinine $>132.6 \mu \mathrm{mol} / \mathrm{L}$ ); anticipated cold ischemia time $\geq 24$ hours; or donation after cardiac death. Patients were treated with basiliximab induction, mycophenolate mofetil, and corticosteroids, and were then randomized to receive either belatacept MI, belatacept LI, or cyclosporine. Lymphocyte-depleting therapy was allowed for anticipated delayed graft function in cyclosporine-treated patients. Patients with acute rejection $\geq$ Grade IIB could be treated with T-cell-depleting therapy at the investigators' discretion.

The primary outcomes were the composite endpoint of patient and graft survival as well as the composite endpoint of renal impairment at 12 months. Note that unlike BENEFIT, BENEFIT-EXT did not include the incidence of acute rejection as a primary outcome measure. The noninferiority margin was set at $10 \%$ for patient and graft survival. Secondary outcomes included measured GFR, calculated GFR using the Modification of Diet in Renal Disease equation, prevalence of biopsy-proven chronic allograft nephropathy, and incidence and severity of biopsy-proven acute rejection. Protocol biopsies were performed at implantation and at week 52. A total of 543 patients were randomized and transplanted $(\mathrm{n}=184 \mathrm{MI}$, $\mathrm{n}=175 \mathrm{LI}, \mathrm{n}=184$ cyclosporine). There were no differences in baseline characteristics between the three groups. 
Both belatacept regimens were noninferior to cyclosporine on the primary endpoint of patient and graft survival. Graft loss or death occurred in $14 \%, 11 \%$, and $15 \%$ of patients treated with MI, LI, and cyclosporine, respectively. The prevalence of biopsy-proven chronic allograft nephropathy was similar between the three groups (MI 45\%, LI 46\%, cyclosporine 52\%). The mean measured GFR at 12 months was $52.1 \mathrm{~mL} / \mathrm{min} / 1.73 \mathrm{~m}^{2}(P=0.0083$ versus cyclosporine), $49.5 \mathrm{~mL} / \mathrm{min} / 1.73 \mathrm{~m}^{2}$ ( $P=0.1039$ versus cyclosporine), and $45.2 \mathrm{~mL} / \mathrm{min} / 1.73 \mathrm{~m}^{2}$ for the MI-treated, LI-treated, and cyclosporine-treated groups, respectively. The difference in measured GFR was significantly better in the MI-treated patients versus the cyclosporine-treated patients $(P=0.0083)$ but was not significantly different for the LI group compared with cyclosporine $(P=0.1039)$.

Mean systolic and diastolic blood pressure was lower for both belatacept groups compared with the cyclosporinetreated group (MI 141/78 mmHg, LI 141/78 mmHg, cyclosporine $150 / 82 \mathrm{mmHg}$ ). The incidence of NODAT was significantly lower in the MI group compared with the cyclosporine group (MI 2\% versus cyclosporine 9\%, $P=0.0308$ ). However, there was no significant difference in NODAT in the LI group compared with cyclosporine (LI $5 \%, P=0.2946$ ). The mean change in non-high-density lipoprotein cholesterol from baseline was significantly different in the $\mathrm{MI}(0.33 \mathrm{mmol} / \mathrm{L})$ and $\mathrm{LI}(0.29 \mathrm{mmol} / \mathrm{L})$ groups compared with cyclosporine $(0.76 \mathrm{mmol} / \mathrm{L}, P=0.0016 \mathrm{MI}$ versus cyclosporine; $P=0.0006 \mathrm{LI}$ versus cyclosporine).

There was no significant difference in the incidence of acute rejection between the three groups (MI 17.9\%, LI $17.7 \%$, cyclosporine $14.1 \%$ ). However, more type IIB rejections occurred in belatacept-treated patients compared with cyclosporine-treated patients (MI 9\%, LI 5\%, cyclosporine $3 \%$ ). The majority of rejections occurred within the first 3 months (81\%), and nearly all occurred within 6 months. The numbers were small, but it should be noted that more patients in the MI group $(n=5)$ experienced more than one episode of acute rejection compared with the LI $(n=1)$ and cyclosporine $(n=2)$ groups. The most common treatment for acute rejection was corticosteroids, whereas T-cell-depleting therapy was used in 13, five, and four patients in the MI, LI, and cyclosporine groups, respectively.

Three-year data are now available for BENEFIT-EXT. ${ }^{27}$ One patient in each treatment group experienced acute rejection after year 2. By 3 years, the rate of acute rejection was $18 \%, 19 \%$, and $16 \%$ for MI-treated, LI-treated, and cyclosporine-treated patients, respectively. Similar to what was found in the BENEFIT study, the development of donor-specific antibodies was lower in belatacept-treated patients. At baseline, the presence of donor-specific antibodies was similar and low across the treatment groups (6\% MI, $5 \% \mathrm{LI}$, and $8 \%$ cyclosporine). The incremental increase in donor-specific antibodies occurred at a lower frequency in belatacept-treated patients compared with cyclosporinetreated patients by year 3 (MI 7\%, LI 6\%, and cyclosporine $15 \%)$. Among those who had acute rejection, the frequency of donor-specific antibodies was 9\% (MI), 6\% (LI), and 26\% (cyclosporine). In regard to renal function at 3 years, the mean calculated GFR in the intention-to-treat population was $42.7 \pm 27.6 \mathrm{~mL} / \mathrm{min} / 1.73 \mathrm{~m}^{2}, 42.2 \pm 25.2 \mathrm{~mL} / \mathrm{min} / 1.73 \mathrm{~m}^{2}$, and $31.5 \pm 22.1 \mathrm{~mL} / \mathrm{min} / 1.73 \mathrm{~m}^{2}$ in MI-treated, LI-treated, and cyclosporine-treated patients. To look at this another way, compared with cyclosporine, both belatacept regimens had more patients with calculated GFR values within chronic kidney disease (CKD) stages 1 and 2 (31\% MI and $22 \%$ LI versus $8 \%$ cyclosporine) and fewer patients within stages 4 and 5 (30\% MI and 27\% LI versus 44\% cyclosporine, Figure 4). This is an important issue because the higher intercept GFR seen in the belatacept-treated patients may translate into improved long-term allograft outcome.

One patient $(0.5 \%)$ in the MI group and two patients (1\%) in the LI group developed PTLD during the 12-month follow-up period. One additional patient in each of the belatacept groups developed PTLD after month 12. Three of the five PTLD patients had negative EBV serology pretransplant. None of the patients who developed PTLD were exposed to lymphocyte-depleting therapy. By 3 years, PTLD was reported in two MI patients and three LI patients; four cases involved the central nervous system and one case (LI) involved the renal allograft and lymph nodes. Four additional cases of PTLD (three LI and one cyclosporine) occurred after 3 years; one case involved the central nervous system (LI), one involved the renal allograft (LI), one involved the gastrointestinal tract (LI), and the other involved bone marrow (cyclosporine).

\section{Rejection on belatacept}

In various studies, certain features of acute rejection episodes have been found to be poor prognostic factors for graft outcome. These features include high Banff grade, association with development of donor-specific antibodies, late rejection, poor renal function after rejection, and recurrent rejection episodes. ${ }^{28-32}$ Belatacept was associated with more rejections that were histologically more severe (higher Banff grade) than cyclosporine-treated patients, but lacked the other characteristics usually associated with poor outcomes. 


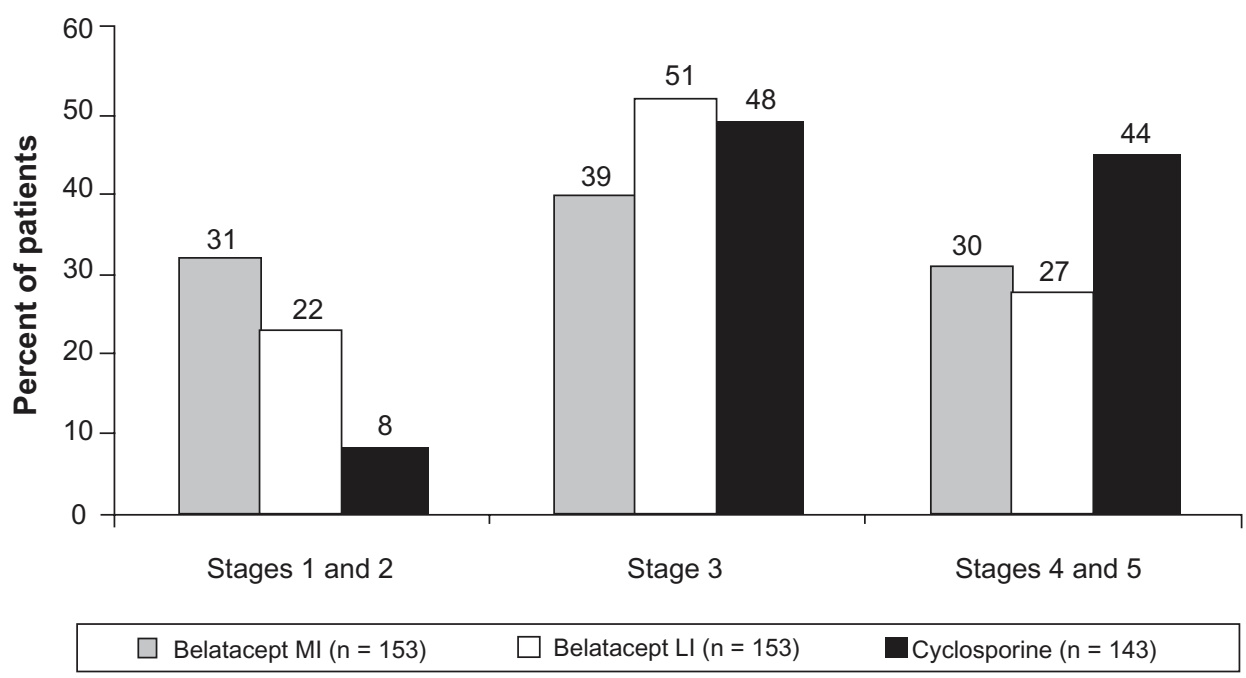

Figure 4 Percentage of patients at chronic kidney disease stages at 3 years in BENEFIT-EXT.

Abbreviation: BENEFIT-EXT, Belatacept Evaluation of Nephroprotection and Efficacy as First-line Immunosuppression Trial-EXTended criteria donors.

There are several possible factors that may help explain the trend of higher rejection rates seen in belatacept-treated patients. Some studies have suggested that memory cells may be resistant to costimulation blockade. ${ }^{33,34}$ Recent data suggest that resistance of memory T-cells to costimulatory blockade can be abrogated when costimulatory blockade is coupled with either anti-VLA-4 (very late antigen-4) or anti-LFA-1 (leukocyte functional antigen-1) antibody blockade. ${ }^{35}$ Both integrins (VLA-4 and LFA-1) play a central role in T-cell activation, effector functions, and trafficking to inflamed tissues. Additionally, T-cell activation may also occur through other costimulation pathways. ${ }^{16}$

It is interesting that the LI regimen in the BENEFIT study was associated with a lower rate of acute rejection compared with the MI regimen. The data suggest that blockade of CD80/86 on the antigen-presenting cell may interfere with the negative signaling that occurs through CTLA-4 engagement and may be required to curtail alloresponses. ${ }^{16}$ As an example, in a Phase II trial utilizing CTLA4Ig in patients with psoriasis, the humoral immune response to keyhole limpet hemocyanin immunization was blunted with lower doses of CTLA4Ig but not with the highest dose. ${ }^{36}$
Lastly, there may be the depletion of important subsets of $T$ regulatory cells. Data have suggested that patients treated chronically with belatacept maintained normal $\mathrm{T}$ regulatory cells; it remains unclear if a subset of adaptive $\mathrm{T}$ regulatory cells may have been adversely affected. ${ }^{37}$

\section{Safety: focus on PTLD}

The major safety concern that has arisen is the development of PTLD in belatacept-treated patients. An integrated safety profile analysis was performed utilizing data from the Phase II trial as well as data from BENEFIT and BENEFIT-EXT. ${ }^{38}$ The pooled analysis included a total of 1425 patients (MI 477, LI 472, cyclosporine 476). The frequency of malignancies was $10 \%, 6 \%$, and $7 \%$ in the MI, LI, and cyclosporine groups, respectively (Table 1). Sixteen cases of PTLD occurred ( $n=8$ MI, $n=6 \mathrm{LI}, \mathrm{n}=2$ cyclosporine), including nine cases involving the central nervous system $(\mathrm{n}=6 \mathrm{MI}, \mathrm{n}=3 \mathrm{LI})$. The risk of PTLD was highest in EBV-negative recipients. Additionally, more PTLD affecting the central nervous system occurred in the MI group. Consequently, when belatacept was approved by the Food and Drug Administration, it was recommended for use only in patients who are seropositive

Table I Incidence of malignancies and PTLD in the pooled analysis from the Phase II and III belatacept trials

\begin{tabular}{llll}
\hline & Belatacept MI $(\mathbf{n}=\mathbf{4 7 7})$ & Belatacept LI $(\mathbf{n}=\mathbf{4 7 2})$ & Cyclosporine $(\mathbf{n}=\mathbf{4 7 6})$ \\
\hline All malignancies & $46(10)$ & $27(6)$ & $34(7)$ \\
PTLD & $8(2)$ & $6(1)$ & $2(<1)$ \\
Malignancies excluding nonmelanoma skin cancer & $30(6)$ & $21(4)$ & $20(4)$ \\
Nonmelanoma skin cancer & $17(4)$ & $7(2)$ & $15(3)$ \\
\hline
\end{tabular}

Note: Values are presented as $\mathrm{n}(\%)$.

Abbreviations: LI, less intensive; MI, more intensive; PTLD, post-transplant lymphoproliferative disease. 
for EBV. ${ }^{39}$ Additionally, it should be noted that only the LI regimen was approved by the Food and Drug Administration for kidney transplant rejection prophylaxis. Lastly, one can abrogate the PTLD risk by avoiding the use of lymphocytedepleting agents to treat acute rejection.

\section{Belatacept and cardiometabolic risk}

An analysis was recently published evaluating the effect of belatacept compared with cyclosporine on cardiovascular and metabolic risk factors. ${ }^{40}$ The analysis included 1209 patients from BENEFIT and BENEFIT-EXT and assessed the cardiovascular and metabolic endpoints (changes in blood pressure, changes in serum lipids, and incidence of NODAT) at month 12. Mean systolic blood pressure was 6-9 mmHg lower and mean diastolic blood pressure was $3-4 \mathrm{mmHg}$ lower in the MI and LI groups versus cyclosporine $(P \leq 0.002)$ across both studies at month 12. Non-high-density lipoprotein cholesterol was lower in the belatacept groups versus cyclosporine ( $P<0.01 \mathrm{MI}$ or LI versus cyclosporine in each study). Serum triglycerides were lower in the belatacept groups versus cyclosporine $(P<0.02 \mathrm{MI}$ or LI versus cyclosporine in each study). In a pooled data analysis, NODAT occurred less often in the belatacept groups versus cyclosporine $(P<0.05 \mathrm{MI}$ or LI versus cyclosporine, Figure 5). When one considers the impact of chronic allograft nephropathy on allograft loss and the effect of hypertension, hyperlipidemia, and diabetes on premature patient death with a functioning allograft due to cardiovascular disease, it becomes clear that an immunosuppression regimen that minimizes these effects has the potential to prolong allograft and patient survival.
The higher rate of chronic allograft nephropathy in cyclosporine-treated patients in BENEFIT/BENEFIT-EXT as well as the significantly better measured GFR by a mean of at least $12.9 \mathrm{~mL} / \mathrm{min} / 1.73 \mathrm{~m}^{2}$ in both belatacept groups compared with the cyclosporine group in BENEFIT suggests a trend toward improved long-term renal function. The 3-year BENEFIT data ${ }^{25}$ demonstrate that the difference between both belatacept groups and cyclosporine in mean calculated glomerular filtration rate (cGFR) was about $21 \mathrm{~mL} / \mathrm{min} / 1.73 \mathrm{~m}^{2}$ at year 3. In BENEFIT-EXT, the 2-year mean measured GFR was $52 \mathrm{~mL} / \mathrm{min} / 1.73 \mathrm{~m}^{2}, 50 \mathrm{~mL} /$ $\min / 1.73 \mathrm{~m}^{2}$, and $45 \mathrm{~mL} / \mathrm{min} / 1.73 \mathrm{~m}^{2}$ for the MI, LI, and cyclosporine groups, respectively ( $P=0.28 \mathrm{MI}$ versus cyclosporine; $P=0.108$ LI versus cyclosporine).${ }^{41}$ Typically, GFR declines by approximately $1-2 \mathrm{~mL} / \mathrm{min} / 1.73 \mathrm{~m}^{2}$ annually in renal allografts and ultimately leads to graft failure. ${ }^{42}$ The BENEFIT/BENEFIT-EXT findings indicate that a higher intercept GFR and a promising GFR stage at 2 and 3 years, if sustained, would result in better preservation of renal function and ultimately in prolonged graft survival.

Blood pressure has emerged as an indicator of allograft and patient survival. Opelz et al have demonstrated that for every $10 \mathrm{mmHg}$ increase in systolic blood pressure above $140 \mathrm{mmHg}$ at one-year post-transplant there is an increased risk of graft failure during the following 6 years. ${ }^{43}$ Adjusting for renal function, there is a $15 \%$ reduction in the rate of allograft survival for each $10 \mathrm{mmHg}$ increase in systolic blood pressure. ${ }^{44}$ For every $10 \mathrm{mmHg}$ increase in blood pressure, there is not only an increased risk of graft failure but also an increased risk of death. ${ }^{45}$ In BENEFIT, there was

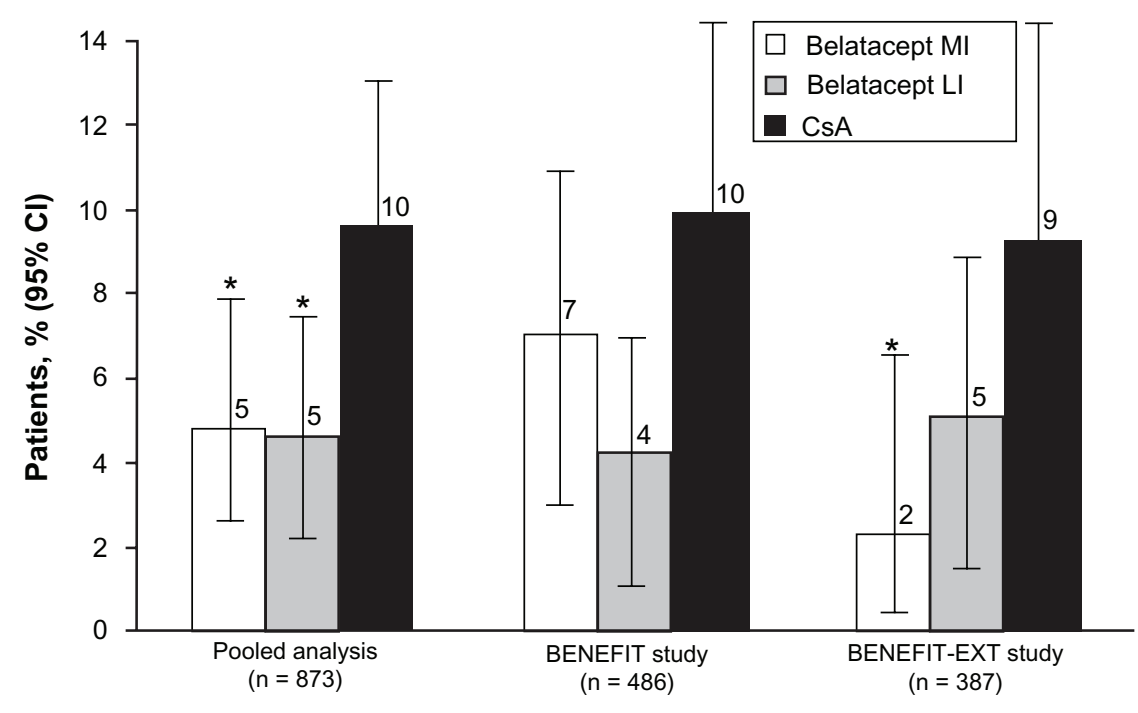

Figure 5 Incidence of new-onset diabetes after transplant in BENEFIT and BENEFIT-EXT and in a pooled analysis of both studies.

Note: ${ }^{*} P<0.05$ versus CsA.

Abbreviation: CsA, cyclosporine. 
a significant improvement of 6-9 $\mathrm{mmHg}$ in mean systolic blood pressure of belatacept-treated patients compared with cyclosporine-treated patients. In BENEFIT-EXT, the mean systolic blood pressure was $150 \mathrm{mmHg}$ in cyclosporinetreated patients, and significantly higher than in belatacepttreated patients. The improvement in blood pressure control in belatacept-treated patients occurred despite the fact that more patients in the two cyclosporine treatment groups required at least three antihypertensive medications compared with the belatacept-treated patients. Improved blood pressure control in belatacept-treated patients will likely translate into improved long-term graft and patient survival.

Non-high-density lipoprotein cholesterol was significantly better in patients treated with belatacept compared with those who received cyclosporine. Dyslipidemia following renal transplant has been associated with greater patient death post-transplant but not graft loss; however, a lower incidence of hyperlipidemia benefits mortality due to cardiovascular events. ${ }^{46}$ Improvements in this risk profile will likely translate into a lower rate of cardiac events and reduce the cardiovascular mortality seen in the renal transplant population.

Avoiding NODAT has important implications for patients following transplant, including less use of diabetic medications, reduced cardiovascular risk, and improved patient and allograft survival. ${ }^{47-49}$ Interestingly, an analysis was also done to evaluate the effect of belatacept use compared with cyclosporine in patients with pre-existing diabetes. ${ }^{50}$ This post hoc analysis evaluated pooled data from BENEFIT and BENEFIT-EXT to assess the effect of belatacept on patient and allograft survival in this high-risk patient population. Of the 1209 patients in the two trials, 336 had pre-existing diabetes. At 12 months, the LI group demonstrated a numerically higher rate of patients surviving with a functioning graft $(90.4 \% \mathrm{MI}, 92.8 \% \mathrm{LI}$, and $80.8 \%$ cyclosporine). However, this difference was not statistically significant. These data are intriguing because they suggest that there may be a patient and allograft survival benefit for patients with pre-existing diabetes with belatacept compared with cyclosporine. However, further studies are necessary to confirm these findings and fully elucidate the benefits belatacept may provide in this high-risk patient group.

\section{Conclusion}

Belatacept, as demonstrated in two large Phase III clinical trials, is noninferior to cyclosporine at one year in patient and graft survival. The incidence of acute rejection was higher in belatacept-treated patients compared with cyclosporinetreated patients. However, despite a higher incidence of rejection, belatacept-treated patients had improved mean measured GFR at one and 2 years. Except for the higher Banff grade, rejections on belatacept were not associated with poor prognostic factors for graft outcomes. Improvements in blood pressure, lipids, and GFR will likely translate into improved long-term patient and graft survival as part of a CNI-avoiding regimen. The risk of PTLD can be modified by selecting EBV-positive recipients and avoiding use of lymphocyte-depleting agents.

\section{Disclosure}

FV received grant support from Bristol-Myers Squibb, Princeton, NJ. DW reports no conflicts of interest in this work.

\section{References}

1. Meier-Kriesche HU, Schold JD, Srinivas TR, Kaplan B. Lack of improvement in renal allograft survival despite a marked decrease in acute rejection rates over the most recent era. Am J Transplant. 2004;4(3):378-383.

2. United States Renal Data System. USRDS 2008 Annual Data Report: atlas of chronic kidney disease and end-stage renal disease in the United States. Available from: http://www.usrds.org/adr.htm. Accessed June 8, 2012.

3. Jevnikar AM, Mannon RB. Late kidney allograft loss: what we know about it, and what we can do about it. Clin J Am Soc Nephrol. 2008;3(Suppl 2):S56-S67.

4. Nankivell BJ, Borrows RJ, Fung CL, O'Connell PJ, Allen RD, Chapman JR. The natural history of chronic allograft nephropathy. N Engl J Med. 2003;349(24):2326-2333.

5. Abramowicz D, Del Carmen Rial M, Vitko S, et al. Cyclosporine withdrawal from a mycophenolate mofetil-containing immunosuppressive regimen: results of a five-year, prospective, randomized study. $J \mathrm{Am}$ Soc Nephrol. 2005;16(7):2234-2240.

6. Ekberg H, Tedesco-Silva H, Demirbas A, et al. Reduced exposure to calcineurin inhibitors in renal transplantation. $N$ Engl J Med. 2007;357(25):2562-2575.

7. Flechner SM, Goldfarb D, Modlin C, et al. Kidney transplantation without calcineurin inhibitor drugs: a prospective, randomized trial of sirolimus versus cyclosporine. Transplantation. 2002;74(8):1070-1076.

8. Larson TS, Dean PG, Stegall MD, et al. Complete avoidance of calcineurin inhibitors in renal transplantation: a randomized trial comparing sirolimus and tacrolimus. Am J Transplant. 2006;6(3):514-522.

9. Schena FP, Pascoe MD, Alberu J, et al. Conversion from calcineurin inhibitors to sirolimus maintenance therapy in renal allograft recipients: 24-month efficacy and safety results from the CONVERT trial. Transplantation. 2009;87(2):233-242.

10. Cosio FG, Grande JP, Wadei H, Larson TS, Griffin MD, Stegall MD. Predicting subsequent decline in kidney allograft function from early surveillance biopsies. Am J Transplant. 2005;5(10):2464-2472.

11. Gaston RS, Cecka JM, Kasiske BL, et al. Evidence for antibodymediated injury as a major determinant of late kidney allograft failure. Transplantation. 2010;90(1):68-74.

12. Gourishankar S, Leduc R, Connett J, et al. Pathological and clinical characterization of the 'troubled transplant': data from the DeKAF study. Am J Transplant. 2010;10(2):324-330.

13. Haririan A, Kiangkitiwan B, Kukuruga D, et al. The impact of c 4 d pattern and donor-specific antibody on graft survival in recipients requiring indication renal allograft biopsy. Am J Transplant. 2009;9(12):2758-2767.

14. Hidalgo LG, Campbell PM, Sis B, et al. De novo donor-specific antibody at the time of kidney transplant biopsy associates with microvascular pathology and late graft failure. Am J Transplant. 2009;9(11): 2532-2541. 
15. Sis B, Jhangri GS, Bunnag S, Allanach K, Kaplan B, Halloran PF. Endothelial gene expression in kidney transplants with alloantibody indicates antibody-mediated damage despite lack of C4d staining. Am J Transplant. 2009;9(10):2312-2323.

16. Li XC, Rothstein DM, Sayegh MH. Costimulatory pathways in transplantation: challenges and new developments. Immunol Rev. 2009;229(1):271-293.

17. Vincenti F. Costimulation blockade in autoimmunity and transplantation. J Allergy Clin Immunol. 2008;121(2):299-306.

18. Larsen CP, Pearson TC, Adams AB, et al. Rational development of LEA29Y (belatacept), a high-affinity variant of CTLA4-Ig with potent immunosuppressive properties. Am J Transplant. 2005;5(3):443-453.

19. Lenschow DJ, Zeng Y, Thistlethwaite JR, et al. Long-term survival of xenogeneic pancreatic islet grafts induced by CTLA4lg. Science. 1992;257(5071):789-792.

20. Latek R, Fleener C, Lamian V, et al. Assessment of belatacept-mediated costimulation blockade through evaluation of CD80/86-receptor saturation. Transplantation. 2009;87(6):926-933.

21. Vincenti F, Larsen C, Durrbach A, et al. Costimulation blockade with belatacept in renal transplantation. $N$ Engl J Med. 2005;353(8): 770-781.

22. Vincenti F, Blancho G, Durrbach A, et al. Five-year safety and efficacy of belatacept in renal transplantation. J Am Soc Nephrol. 2010;21(9):1587-1596.

23. Vincenti F, Charpentier B, Vanrenterghem Y, et al. A phase III study of belatacept-based immunosuppression regimens versus cyclosporine in renal transplant recipients (BENEFIT study). Am J Transplant. 2010;10(3):535-546.

24. Larsen CP, Grinyo J, Medina-Pestana J, et al. Belatacept-based regimens versus a cyclosporine A-based regimen in kidney transplant recipients: 2-year results from the BENEFIT and BENEFIT-EXT studies. Transplantation. 2010;90(12):1528-1535.

25. Vincenti F, Larsen CP, Alberu J, et al. Three-year outcomes from BENEFIT, a randomized, active-controlled, parallel-group study in adult kidney transplant recipients. Am J Transplant. 2012;12(1):210-217.

26. Durrbach A, Pestana JM, Pearson T, et al. A Phase III study of belatacept versus cyclosporine in kidney transplants from extended criteria donors (BENEFIT-EXT study). Am J Transplant. 2010;10(3):547-557.

27. Pestana JO, Grinyo JM, Vanrenterghem Y, et al. Three-year outcomes from BENEFIT-EXT: a Phase III study of belatacept versus cyclosporine in recipients of extended criteria donor kidneys. Am J Transplant. 2012;12(3):630-639.

28. Everly MJ, Everly JJ, Arend LJ, et al. Reducing de novo donor-specific antibody levels during acute rejection diminishes renal allograft loss. Am J Transplant. 2009;9(5):1063-1071.

29. Opelz G, Dohler B. Influence of time of rejection on long-term graft survival in renal transplantation. Transplantation. 2008;85(5):661-666.

30. Racusen LC, Colvin RB, Solez K, et al. Antibody-mediated rejection criteria - an addition to the Banff 97 classification of renal allograft rejection. Am J Transplant. 2003;3(6):708-714.

31. Tanaka T, Kyo M, Kokado Y, et al. Correlation between the Banff 97 classification of renal allograft biopsies and clinical outcome. Transpl Int. 2004;17(2):59-64.

32. Vereerstraeten P, Abramowicz D, de Pauw L, Kinnaert P. Absence of deleterious effect on long-term kidney graft survival of rejection episodes with complete functional recovery. Transplantation. 1997;63(12): 1739-1743.

Biologics: Targets \& Therapy

\section{Publish your work in this journal}

Biologics: Targets \& Therapy is an international, peer-reviewed journal focusing on the patho-physiological rationale for and clinical application of Biologic agents in the management of autoimmune diseases, cancers or other pathologies where a molecular target can be identified This journal is indexed on PubMed Central, CAS, EMBase, Scopus
33. Adams AB, Pearson TC, Larsen CP. Heterologous immunity: an overlooked barrier to tolerance. Immunol Rev. 2003;196:147-160.

34. Lakkis FG, Sayegh MH. Memory T cells: a hurdle to immunologic tolerance. J Am Soc Nephrol. 2003;14(9):2402-2410.

35. Kitchens WH, Haridas D, Wagener ME, et al. Integrin antagonists prevent costimulatory blockade-resistant transplant rejection by CD8(+) memory T cells. Am J Transplant. 2012;12(1):69-80.

36. Abrams JR, Lebwohl MG, Guzzo CA, et al. CTLA4Ig-mediated blockade of T-cell costimulation in patients with psoriasis vulgaris. J Clin Invest. 1999;103(9):1243-1252.

37. Bluestone JA, Liu W, Yabu JM, et al. The effect of costimulatory and interleukin 2 receptor blockade on regulatory $\mathrm{T}$ cells in renal transplantation. Am J Transplant. 2008;8(10):2086-2096.

38. Grinyo J, Charpentier B, Pestana JM, et al. An integrated safety profile analysis of belatacept in kidney transplant recipients. Transplantation. 2010;90(12):1521-1527.

39. Food and Drug Administration. Highlights of prescribing information - Nulojix. Available from: http:/www.accessdata.fda. gov/drugsatfda_docs/label/2011/125288s0000 lbl.pdf. Accessed June 8, 2012.

40. Vanrenterghem Y, Bresnahan B, Campistol J, et al. Belataceptbased regimens are associated with improved cardiovascular and metabolic risk factors compared with cyclosporine in kidney transplant recipients (BENEFIT and BENEFIT-EXT studies). Transplantation. 2011;91(9):976-983.

41. Durrbach A, Pestana JM, Pearston T, et al. Belatacept vs cyclosporine in ECD kidney transplants: two-year outcomes from the BENEFIT-EXT study. Am J Transplant. 2010;10(Suppl 4):1.

42. Gill JS, Tonelli M, Mix CH, Pereira BJ. The change in allograft function among long-term kidney transplant recipients. J Am Soc Nephrol. 2003;14(6):1636-1642.

43. Opelz G, Wujciak T, Ritz E. Association of chronic kidney graft failure with recipient blood pressure. Collaborative Transplant Study. Kidney Int. 1998;53(1):217-222.

44. Mange KC, Cizman B, Joffe M, Feldman HI. Arterial hypertension and renal allograft survival. JAMA. 2000;283(5):633-638.

45. Kasiske BL, Anjum S, Shah R, et al. Hypertension after kidney transplantation. Am J Kidney Dis. 2004;43(6):1071-1081.

46. Wissing KM, Abramowicz D, Broeders N, Vereerstraeten P. Hypercholesterolemia is associated with increased kidney graft loss caused by chronic rejection in male patients with previous acute rejection. Transplantation. 2000;70(3):464-472.

47. Cole EH, Johnston O, Rose CL, Gill JS. Impact of acute rejection and new-onset diabetes on long-term transplant graft and patient survival. Clin J Am Soc Nephrol. 2008;3(3):814-821.

48. Cosio FG, Kudva Y, van der Velde M, et al. New onset hyperglycemia and diabetes are associated with increased cardiovascular risk after kidney transplantation. Kidney Int. 2005;67(6):2415-2421.

49. Kasiske BL, Snyder JJ, Gilbertson D, Matas AJ. Diabetes mellitus after kidney transplantation in the United States. Am J Transplant. 2003;3(2):178-185.

50. Rostaing L, Neumayer HH, Reyes-Acevedo R, et al. Belataceptversus cyclosporine-based immunosuppression in renal transplant recipients with pre-existing diabetes. Clin J Am Soc Nephrol. 2011;6(11):2696-2704.

\section{Dovepress}

and the Elsevier Bibliographic databases. The manuscript management system is completely online and includes a very quick and fair peerreview system, which is all easy to use. Visit http://www.dovepress. com/testimonials.php to read real quotes from published authors. 